www.jmscr.igmpublication.org

Impact Factor 5.84

Index Copernicus Value: 71.58

ISSN (e)-2347-176x ISSN (p) 2455-0450

crossref DOI: _https://dx.doi.org/10.18535/jmscr/v5i11.122

Journal Of Medical Science And Clinical Research

IGM Publication

An Official Publication of IGM Publication

\title{
Ostomy in Acute Abdominal Conditions: A Study of 30 Cases
}

\author{
Authors \\ Dr Arvind Kumar Prabhat ${ }^{1}$, Dr Niranjan Dash², Dr J.M. Gadekar ${ }^{3}$, \\ Dr Mrs. V.J.Thipse ${ }^{4}$ \\ ${ }^{1}$ Postgraduate Student, ${ }^{2,4}$ Professor, ${ }^{3}$ Professor and Head of Department
}

Department of General Surgery, DVVPF's Medical College and Hospital, Ahmednagar, Maharashtra, India

\begin{abstract}
Background: Ostomy is an approved surgical option for management of bowel dysfunction and anatomical bowel anomalies, which may results in peritonitis and sepsis, leading to multi-organ failure.

Aim and Objective: To study the feasibility and outcome of ostomy in cases of acute abdomen.

Materials and Methods: We prospectively analyzed 30 cases of acute abdomen, undergoing intestinal stoma formation, following emergency laparotomies in the department of surgery, DVVPF'S Medical College and Hospital, Ahmednagar, Maharashtra during the study period of January 1, 2014 to March 1, 2017. The clinical diagnosis was supported by X-ray erect abdomen, ultrasonography and Contast-enhanced computed tomography.

Results: The study comprised of 30 patients with the mean age of 58 years, with 26 males and 4 females patients. Out of thirty patients of ostomy recruited for the study, 18(60\%) and 12(40\%) patients underwent colostomies and ileostomies respectively. Colostomy was performed on 18 patients out of which $4(13 \%)$ patients suffered from sigmoid volvulus, 2(7\%) patients from rectal perforation, 2(7\%) patients from carcinoma rectum, 2(7\%) patients with rectosigmoid tumor secondary to ovarian carcinoma, 1(3\%) patient with intestinal adhesion, 2(7\%) patients with splenic flexure neoplastic mass, and 5(16\%) patients with cancer sigmoid colon. Temporary Colostomy was performed in 14(78\%) patients and Permanent colostomy in 4(22\%) patients. Among colostomy patients, 2(11\%) patients died. Cause of death was multiorgan failure. Low Anterior Resection (LAR) with ileostomy was performed in 12(40\%) cases of carcinoma rectum. 2(8\%) patients of ileostomy had died due to anastomotic leakage.

Conclusion: Ostomy is a salvage procedure in saving life of the acute abdomen patients in an emergency setting. This is the preferred surgical option especially for palliation before neoadjuvant chemotherapy and in high risk patients that are not fit for emergency definitive surgery. Protective stoma effectively decreases the incidence of anastomotic leak, post-operative ileus, wound infection, small bowel obstruction, morbidity, mortality and recurrence in cases of bowel pathology.

Keywords: Carcinoma rectum; Colostomy; Ileostomy; Peritonitis; Sepsis.
\end{abstract}

\section{Introduction}

Ostomy is a surgical procedure in which an artificial outlet (stoma) for the faeces and flatus, either temporary or permanent is formed by drawing the healthy end of the bowel through an incision in the anterior abdominal wall and suturing it into place with the skin surface. This is also known as bowel diversion. 
An acute abdomen results in peritonitis and sepsis leading to multi-organ failure with high rate of morbidity and mortality. ${ }^{(1,2)} 15-20 \%$ of colonic malignancies present with acute intestinal obstruction. Intestinal obstruction is one of the most common cause of acute abdomen world wide. ${ }^{(3)} 60-70 \%$ of acute abdomen is caused by tumoral obstruction in the colorectal and anal regions. The rest $30 \%$ consist of diverticular disease, inflammatory disease, pelvic malignancies and pseudo-obstruction like Ogilvie syndrome. In 1793, Duret performed the first successful colostomy for imperforate anus in a 3 day old newborn. ${ }^{(4)}$

Colorectal cancer (CRC) is the third most common cancer in males and females. The life time risk of developing colorectal cancer is about $6 \% .^{(5)}$ LAR with protective stoma could effectively reduce the clinical consequences of anastomotic leakage, post-operative ileus and wound infections. ${ }^{(6)}$ Anastomotic leakage can increase morbidity and mortality, prolong the duration of the hospital stay and affect the short or long term quality of life. ${ }^{(7)}$. Recent studies have established that the use of a protective stoma can reduce morbidity and mortality in LAR for rectal cancer. $^{(8)}$

General condition of the patient, extent of generalized peritonitis and the type of ostomy (temporary or permanent) are the factors affecting the cource of clinical status. ${ }^{(9)}$ Along with clinical examination, abdominal sonography, x-ray erect abdomen and CECT abdomen, will be helpful in reaching at final diagnosis. CECT abdomen is a better diagnostic modality in a case with peritonitis.

In our study, we included the cases of acute abdomen which had lead to a procedure requiring ostomy and evaluated the outcome by using the following parameters: American Society of Anaesthesiologist (ASA) and Mannheim Peritonitis Index (MPI) scores, laboratory and radiological findings, etiology and localization of extent of peritonitis, type of surgical procedure and rate of post-operative morbidity and mortality.
In this study, we are trying to prevent the complications of bowel pathology, so that a ostomy can be performed to reduce morbidity and mortality. A surgical procedure may not only treat disease but also affect the patient's quality of life. Therefore, quality of life should be measured in order to assess the impact of disease and surgical procedure.

\section{Materials and Methods}

Between January 1, 2014 to March 1, 2017, thirty consecutive patients with acute abdomen were recruited prospectively from Department of surgery, DVVPF'S Medical college and hospital, Ahmednagar, Maharashtra.

\section{Inclusion Criteria}

- All patients with diagnosis of acute abdomen, who were admitted to surgical ward and undergoing emergency surgery.

- Age group: 46-75 years.

- Both sexes.

\section{Exclusion Criteria:}

- Cases where ostomy was not performed.

- Pediatric age group (0-12 years).

Stoma formation was done using a standard technique of circular skin opening, incision of anterior and posterior rectus sheath, muscle splitting, placing a plastic rod or soft latex drain around the bowel, at the site chosen for ostomy, bowel exteriorization and placement of Mersilk 20 suture from seromuscular layer of intestine to the full thickness of skin. Follow-up was carried out after hospital discharge for a period of three months.

In all cases, exploratory laparotomy was performed under general anaesthesia. In patients with colonic pathology, we performed temporary and permanent ostomy. Temporary ostomy was performed in the form of sigmoid colostomy, transverse colostomy, Hartmann's colostomy and LAR with ileostomy in cases of sigmoid volvulus, intestinal adhesion, splenic flexure neoplastic mass, cancer of sigmoid colon, rectosigmoid tumor secondary to ovarian tumor, rectal perforation and carcinoma rectum. Permanent 
ostomy was performed in the form of sigmoid resection and end colostomy, sigmoid end colostomy in cases of sigmoid volvulus and cancer of sigmoid colon.

Data was analysed using the Chi-Square test where appropriate $\mathrm{P}<0.05$ was considered significant.

Confidence level of $95 \%$ was specified.

Margin of error was 5\%. Therefore:

$$
N=Z^{2(\alpha / 2)}\left[p(1-p) / d^{2}\right]
$$

Where $\mathrm{N}=$ sample size

$\mathrm{p}=$ Proportion of patients with acute abdomen

$\mathrm{d}=$ marginal error between sample and population $(0.05)$

\section{Results}

Patient characteristics are summarized in Table 1. There were 30 patients in the study, 26(87\%) Male and 4(13\%) Female. Mean age was 58 years (range 46-75). Mean hospital stay was 48 days (range 15-90). Hospital deaths were 4(13\%).

Table 1- Characteristics of patients

\begin{tabular}{|l|c|}
\hline Male & $26(87 \%)$ \\
\hline Female & $4(13 \%)$ \\
\hline Mean age (Range) in years & $58(46-75)$ \\
\hline Mean hospital stay in days & $48(15-90)$ \\
\hline Hospital deaths in days & $4(13 \%)$ \\
\hline
\end{tabular}

Values are mean and range or number of patients percentage

Table 2- Distribution of cases: colonic pathology was present in 12(39\%) cases. Rectosigmoid tumor was present in $2(7 \%)$ cases and pathology in the rectum was present in $16(54 \%)$ cases.

\begin{tabular}{|l|c|c|}
\hline Site involved & Etiology & Number of cases (n) \\
\hline \multirow{4}{*}{ Colon } & Sigmoid volvulus & $4(13 \%)$ \\
\cline { 2 - 3 } & Cancer of sigmoid colon & $5(16 \%)$ \\
\cline { 2 - 3 } & $\begin{array}{c}\text { Intestinal adhesion } \\
\text { (Descending colon) }\end{array}$ \\
\hline \multirow{2}{*}{ Rectosigmoid junction } & Splenic flexure neoplastic mass & $1(3 \%)$ \\
\cline { 2 - 3 } & $\begin{array}{c}\text { Rectosigmoid tumor secondary to } \\
\text { ovarian carcinoma }\end{array}$ & $2(7 \%)$ \\
\hline Rectum & Rectal perforation & $2(7 \%)$ \\
\hline & Carcinoma rectum & $14(47 \%)$ \\
\hline
\end{tabular}

Table 3 - Types of ostomy done in acute abdomen: Colostomy was performed in 18(60\%) cases [Temporary in $14(78 \%)$ cases and Permanent in $4(22 \%)$ cases] and ileostomy was performed in $12(40 \%)$ cases.

\begin{tabular}{|c|c|c|c|}
\hline \multicolumn{3}{|c|}{ Surgical procedure } & Number of patients \\
\hline & & Etiology & \\
\hline \multirow[b]{2}{*}{$\begin{array}{c}\text { Colostomy } \\
18(60 \%)\end{array}$} & $\begin{array}{l}\text { Temporary } \\
\text { colostomy }\end{array}$ & $\begin{array}{c}\text { Sigmoid volvulus } \\
\text { Intestinal adhesion (Descending colon) } \\
\text { Splenic flexure neoplastic mass } \\
\text { Cancer of sigmoid colon } \\
\text { Rectosigmoid tumor secondary to ovarian tumor } \\
\text { Rectal perforation } \\
\text { Carcinoma rectum }\end{array}$ & $14(78 \%)$ \\
\hline & $\begin{array}{l}\text { Permanent } \\
\text { Colostomy }\end{array}$ & $\begin{array}{c}\text { Sigmoid volvulus } \\
\text { Cancer of sigmoid colon }\end{array}$ & $4(22 \%)$ \\
\hline \multicolumn{2}{|c|}{ Ileostomy $12(40 \%)$} & Carcinoma rectum & $12(40 \%)$ \\
\hline
\end{tabular}


Management and Outcomes: Table no. 4: Summarizes the overall surgical procedure and rate of morbidity and mortality (by ASA and MPI). Benign lesion was present in 5(17\%) cases and malignant lesion in 25(83\%) cases. Higher the ASA \& MPI score, higher is the morbidity and mortality. Mortality was reported in 4(13\%) cases. LAR with ileostomy was performed in majority of cases of carcinoma rectum.

\begin{tabular}{|c|c|c|c|c|c|}
\hline $\begin{array}{l}\text { Site } \\
\text { Involved }\end{array}$ & Etiology & Surgical procedure & $\begin{array}{c}\text { Benign/ } \\
\text { Malignant lesion }\end{array}$ & $\begin{array}{l}\text { ASA/MPI } \\
\text { score }\end{array}$ & $\begin{array}{l}\text { Morbidity/ } \\
\text { Mortality }\end{array}$ \\
\hline \multirow{12}{*}{ Colon } & Sigmoid volvulus & $\begin{array}{l}\text { Sigmoid resection and } \\
\text { end colostomy }\end{array}$ & Benign & $3 / 15$ & $-/-$ \\
\hline & Sigmoid volvulus & Sigmoid colostomy & Benign & $4 / 21$ & $+/-$ \\
\hline & Sigmoid volvulus & Sigmoid colostomy & Benign & $4 / 18$ & $-1-$ \\
\hline & Sigmoid volvulus & $\begin{array}{l}\text { Sigmoid resection and } \\
\text { end colostomy }\end{array}$ & Malignant & $3 / 9$ & $-1-$ \\
\hline & $\begin{array}{l}\text { Intestinal-adhesion } \\
\text { (Descending colon) }\end{array}$ & Transverse colostomy & Benign & $4 / 19$ & $+/-$ \\
\hline & $\begin{array}{c}\text { Splenic flexure neoplastic } \\
\text { mass }\end{array}$ & Transversecolostomy & Malignant & $4 / 20$ & $+/+$ \\
\hline & $\begin{array}{l}\text { Splenic flexure neoplastic } \\
\text { mass }\end{array}$ & Transverse colostomy & Malignant & $3 / 19$ & $-1-$ \\
\hline & Cancer of sigmoid colon & Hartmann's colostomy & Malignant & $3 / 18$ & $-1-$ \\
\hline & Cancer of sigmoid colon & Sigmoid end colostomy & Malignant & $3 / 15$ & $-1-$ \\
\hline & Cancer of sigmoid colon & Transverse colostomy & Malignant & $3 / 19$ & $+/-$ \\
\hline & Cancer of sigmoid colon & Sigmoid colostomy & Malignant & $3 / 21$ & $-1-$ \\
\hline & Cancer of sigmoid colon & Sigmoid end colostomy & Malignant & $3 / 18$ & $+/-$ \\
\hline \multirow{2}{*}{$\begin{array}{l}\text { Recto- } \\
\text { sigmoid } \\
\text { junction }\end{array}$} & $\begin{array}{c}\text { Rectosigmoid tumor } \\
\text { secondary to ovarian tumor }\end{array}$ & Transverse colostomy & Malignant & $4 / 26$ & $+/+$ \\
\hline & $\begin{array}{c}\text { Rectosigmoid tumor } \\
\text { secondary to ovarian tumor }\end{array}$ & Sigmoid colostomy & Malignant & $3 / 19$ & $-/-$ \\
\hline \multirow{16}{*}{ Rectum } & Rectal perforation & Sigmoid colostomy & Malignant & $3 / 18$ & $-1-$ \\
\hline & Rectal perforation & Sigmoid colostomy & Benign & $4 / 16$ & $+/-$ \\
\hline & Carcinoma rectum & Hartmann's colostomy & Malignant & $3 / 21$ & $+/-$ \\
\hline & Carcinoma rectum & Transverse colostomy & Malignant & $3 / 19$ & $+/-$ \\
\hline & Carcinoma rectum & LAR with ileostomy & Malignant & $4 / 26$ & $+/+$ \\
\hline & Carcinoma rectum & LAR with ileostomy & Malignant & $3 / 19$ & $-/-$ \\
\hline & Carcinoma rectum & LAR with ileostomy & Malignant & $2 / 20$ & $-1-$ \\
\hline & Carcinoma rectum & LAR with ileostomy & Malignant & $3 / 18$ & $-1-$ \\
\hline & Carcinoma rectum & LAR with ileostomy & Malignant & $4 / 10$ & $-/-$ \\
\hline & Carcinoma rectum & LAR with ileostomy & Malignant & $3 / 16$ & $-1-$ \\
\hline & Carcinoma rectum & LAR with ileostomy & Malignant & $4 / 18$ & $+/-$ \\
\hline & Carcinoma rectum & LAR with ileostomy & Malignant & $3 / 16$ & $-/-$ \\
\hline & Carcinoma rectum & LAR with ileostomy & Malignant & $3 / 18$ & $-/-$ \\
\hline & Carcinoma rectum & LAR with ileostomy & Malignant & $3 / 26$ & $+/+$ \\
\hline & Carcinoma rectum & LAR with ileostomy & Malignant & $4 / 16$ & $-/-$ \\
\hline & Carcinoma rectum & LAR with ileostomy & Malignant & $3 / 18$ & $-1-$ \\
\hline
\end{tabular}

Table 5 - Organ failure in patients with acute abdomen: Mortality was reported in 4 cases because of multiple organ failure and sepsis secondary to anastomotic leakage. Metabolic disorder was also present in one of the case.

\begin{tabular}{|l|c|c|c|}
\hline Diagnosis & Types of ostomy done & Cause of death & No of patients \\
\hline $\begin{array}{l}\text { Splenic flexure neoplastic } \\
\text { mass }\end{array}$ & Transverse colostomy & Multiple organ failure & $2(7 \%)$ \\
\hline Carcinoma rectum tumor & LAR with ileostomy & Pulmonary insufficiency & $2(7 \%)$ \\
\hline $\begin{array}{l}\text { Rectosigmoid } \\
\text { secondary to ovarian tumor }\end{array}$ & LAR with ileostomy & Cardiovascular insufficiency & $1(3 \%)$ \\
\hline Carcinoma rectum flexure neoplastic & Transverse colostomy & Metabolic disorders & $2(7 \%)$ \\
\hline $\begin{array}{l}\text { Splenic } \\
\text { mass }\end{array}$ & LAR with ileostomy & Sepsis secondary to anastomotic leakage & $1(3 \%)$ \\
\hline Carcinoma rectum & & $2(7 \%)$ \\
\hline
\end{tabular}


Table 6 - Electrolyte disturbances in ileostomy: Hypokalemia is the commonest electrolyte imbalance.

\begin{tabular}{|l|c|c|c|}
\hline Diagnosis & Types of ostomy done & Electrolyte imbalance & Number of patients \\
\hline Carcinoma rectum & LAR with ileostomy & Hypokalemia & $10(83 \%)$ \\
\hline Carcinoma rectum & LAR with ileostomy & Hyponatremia & $4(33 \%)$ \\
\hline Carcinoma rectum & LAR with ileostomy & None & $2(16 \%)$ \\
\hline
\end{tabular}

Table 7 - Ostomy related complications: Skin excoriation was present in the majority of cases. Parastomal hernia was also reported in 3(10\%) cases.

\begin{tabular}{|c|c|c|c|}
\hline Diagnosis & Types of ostomy done & Complications & Number of patients \\
\hline Sigmoid volvulus & Sigmoid colostomy & \multirow{5}{*}{ Skin Excoriation } & \multirow{5}{*}{$19(63 \%)$} \\
\hline Cancer of sigmoid colon & Hartmann's colostomy & & \\
\hline Cancer of sigmoid colon & Sigmoid colostomy & & \\
\hline Carcinoma rectum & LAR with ileostomy & & \\
\hline Splenic flexure neoplastic mass & Transverse colostomy & & \\
\hline Carcinoma rectum & LAR with ileostomy & \multirow{3}{*}{ Parastomal hernia } & \multirow{3}{*}{$3(10 \%)$} \\
\hline Sigmoid volvulus & $\begin{array}{l}\text { Sigmoid resection and end } \\
\text { colostomy }\end{array}$ & & \\
\hline Cancer of sigmoid colon & Sigmoid colostomy & & \\
\hline
\end{tabular}

\section{Follow up}

During the study period, patients were followed upto a period of 3 months following which reversal of temporary ostomy was done. In cases of Permanent ostomy, there were no complications of surgical management nor readmission.

\section{Discussion}

Ostomy is a life saving surgical procedure, required in number of acute abdomen. Ostomy is also very important procedure prior to definitive surgery and for palliation before neoadjuvant chemotherapy and radiotherapy.

In our study, mean age in years was 58 years (4675). In other studies one including Kenan Büyükaşık et al, mean age was 64.8 years (25-87). Male:Female patients in our study was $26: 4$, as compaired to 59:46 in Kenan Büyükaşık et al study. This variation in sex ratio is difficult to explain and needs further study. 21(70\%) patients with acute abdomen had tumor in rectosigmoid region. The remaining reason were sigmoid volvulus in $4(13 \%)$ cases and intestinal adhesion in $1(3 \%)$ case. But in Kenan Büyükaşık et al study tumor in rectosigmoid region were seen in $66(62.8 \%)$ cases, sigmoid volvulus in $10(9.5 \%)$ cases and intestinal adhesion in $8(7.6 \%)$ cases. $^{(10)}$ This shows similar results of Kenan Büyükaşık et al.
Rectal carcinoma is a devastating malignancy worldwide. Sphincter preservation is the need of the hour. Distal anastomosis is more prone to leaks. Proximal diversion in form of ileostomy or colostomy is used to protect distal anastomosis by reducing the intraluminal pressure.

Recent studies have demonstrated that the use of diverting stoma is an effective and safe procedure to prevent anastomotic leakage after sphincter saving surgery in low anterior resection for rectal cancer. This statement is supported by data from various randomized studies that have been subjected to meta-analysis, showing an improvement in outcome associated with protective stoma with LAR. ${ }^{(11,12)}$ In our study, twelve cases of LAR with ileostomy were performed in which anastomotic leakage were present in $2(7 \%$ ) cases. In one of the study, Matthiessen $\mathrm{P}$ et al anastomotic leakage was present in 12 $(10.17 \%) .{ }^{(13)}$ When there is anastomotic leakage, it increases morbidity, mortality, prolongs the duration of hospital stay and affects the short or long-term quality of life. ${ }^{(7)}$ In our study, fourteen cases of rectal carcinoma were reported. In twelve cases LAR with ileostomy, in one case transverse colostomy and in other case Hartmann's colostomy was done. LAR with ostomy has certain advantages over LAR without ostomy in terms of anastomotic leak, post-operative ileus, wound infection, small bowel obstruction, 
resumption of diet and in terms of mortality and recurrence.

LAR is generally performed for lesions in the upper and middle third of the rectum and occasionally for lesions in the lower third. In our series lesions in the upper, middle and lower third of rectum were present in six, five and one cases respectively. Anastomotic leak ranges from 3$11 \%$ for upper and middle third anastomosis and to $20 \%$ for lower-third anastomosis. ${ }^{(14)}$ In our study, anastomotic leakage were present in $2(7 \%)$ cases, one in middle third and another one in lower third of rectum. Proximal diversion in the form of ostomy is adopted because of the high rates of anastomotic complications associated with low colorectal and coloanal anastomosis. ${ }^{(15)}$ The formation of protective stomas for stool diversion after restorative procedures have been reported to have a great impact on surgical morbidity and mortality of restorative colorectal surgery. ${ }^{(8)}$

Guloglu et $\mathrm{al}^{(16)}$ reported morbidity rates as $44 \%$ and mortality rate as $31 \%$, while Ertekin et al ${ }^{(2)}$ reported morbidity rates as $42 \%$ and mortality rates as $33 \%$ in their studies. Shinkawa et $\mathrm{al}^{(1)}$ reported a mortality rate of $17.5 \%$. In our study, the rates of morbidity and mortality were 40 and $13.3 \%$ respectively. These results are same as our study results.

Intestinal obstruction is one of the most common cause of non-traumatic acute abdomen world wide. ${ }^{(3)}$ In the institutional series (2015-2016) of 357 study subjects, $181(50.7 \%)$ patients had intestinal obstruction, while in our case series out of $30,12(40 \%)$ patients had intestinal obstruction. ${ }^{(17)}$ It needs further study to opine for variation of incidence. Colostomy was performed in intestinal obstruction present at the left side of the colon, as a bridge to definitive surgical procedure and in patients in whom surgery was not possible. It provides decompression of colon with minimal surgical trauma and helps in evaluation of the patient for definitive treatment.

The Sigmoid colon is the most common location for volvulus, diverticulitis and tumors in the nontraumatic setting followed by rectum. Hellinger and Steinhagen study shows $\sim 60 \%$ of intestinal volvulus involving the sigmoid colon. ${ }^{(18)}$ In our study sigmoid volvulus accounts $4(13 \%)$ cases. Variation in these two results needs further study. Tumors of the colon distal to transverse colon have higher rates of morbidity and mortality, thus requiring permanent or temporary colostomy. ${ }^{(19)}$ In our study, mortality of two patients was there in which tumor was present distal to the transverse colon. In advanced stage of colorectal cancer, chance of perforation is high. Morbidity and mortality rates in these cases are higher than other etiologies. In our study, 2(7\%) cases of rectal perforation were reported. In the Abdelrazeq AS et $\mathrm{al}^{(20)}$ study, rectal perforation was present in $1.2-10 \%$.

In 1921, Hartmann described an operation for the removal of carcinoma from the rectum and lower sigmoid colon as an alternative to abdominoperineal resection. ${ }^{(21)}$ This procedure consisted of excision of the lesion, oversewing of the rectal stump and bringing out the sigmoid colon as a terminal colostomy. Ninety-seven patients underwent Hartmann's procedure in the institutional series (1981-1986), ${ }^{(22)}$ while in our institutional series, this procedure were done in two cases, one for cancer of sigmoid colon and other for rectal carcinoma. In the institutional series (1981-1986), the mean hospital stay was 23 days \pm 13 days for the initial Hartmann's procedure and 15 days \pm 5 days for restoration of intestinal continuity. In our institutional series mean hospital stay was 20 days \pm 8 days for initial Hartmann's procedure and 10 days \pm 5 days for restoration of intestinal continuity. ${ }^{(23)}$ This procedure is generally performed for disease of the Sigmoid colon.

Electrolyte imbalance is the major disadvantage with an ileostomy. Hypokalemia is the commonest electrolyte imbalance. Ambren et al found electrolyte imbalance in $5.8 \%$ of patients. ${ }^{(24)}$ In our study, we found electrolyte imbalance in $83 \%$ of patients. Disparity in these two results is difficult to explain. 
Ostomy construction and closure is associated with considerable morbidity and increased costs. The major disadvantages of ostomy include the need for another operation, a longer hospital stay and ostomy related complications, such as parastomal hernia, stomal prolapse, ischaemic necrosis, peristomal abscess, chemical dermatitis, peristomal fistula, diarrhoea and dehydration, skin excoriation and stomal stenosis. ${ }^{(25,26)}$ In one of the study, Prashant Raj Pipariya et al, ${ }^{(27)}$ reported parastomal hernia in $3(6 \%)$ cases and skin excoriation in $8(16 \%)$ cases. In our study, skin excoriation was present in $19(63 \%)$ patients and parastomal hernia in $3(10 \%)$ patients. Skin excoriation was conservatively managed, while parastomal hernia was successfully repaired.

Before stoma closure, each patient underwent loopogram to check distal patency. In G.Vrakas et al study, the time from stoma construction to its closure for the patient with no adjuvant therapy was three months and for those with adjuvant therapy was seven months. In our study, the duration for stoma construction to its closure for the patients with no adjuvant therapy was one month and for those with adjuvant therapy was six months. (28)

Ostomy patients experience many challenges in relation to their quality of life (QOL). Living with stoma influences the overall aspect of QOL. Education for the patients and their families is important for improving the stoma patients QOL. Sexual and Psychological consultation may also improve patients QOL. ${ }^{(29)}$ In our study, psychological and social problem was present in 7(23.3\%) patients like depression, anxiety and stress, while in one of the study Richbourg L et al (30) these problem were present in $53 \%$ of patients.

\section{Conclusion}

Ostomy is a salvage procedure in saving life of the patient in an emergency setting and has a profound effect on outcome. This surgical procedure definitely reduced the significant associated morbidity and mortality. Low anterior resection (LAR) with protective stoma effectively decreases the incidence of anastomotic leak, postoperative ileus, wound infection, small bowel obstruction, morbidity, mortality and recurrence in cases of carcinoma rectum. Although ostomy is a life saving surgical procedure, not many studies are found in literature depicting its effect on morbidity and mortality, So it needs further studies.

\section{References}

1. Shinkawa H, Yasuhara $H$, Naka $S$ et al Factors affecting the early mortality of patients with nontraumatic colorectal perforation. Surg Today 2003;33:13-17.

2. Ertekin $\mathrm{C}$, İğci $\mathrm{A}$, Taviloğlu $\mathrm{K}$ et al Nontraumatik kolon perforasyonlar1. Ulusal Cerrahi Dergisi 1991;7:185-189.

3. Gainant A (2012) Emergency management of acute colonic cancer obstruction. J Visc Surg 2012;3-10:149(1).

4. DINNICK, T. British Journal of Surgery 1934; 22, 142.

5. E.T. Hawk, B. Levin, Colorectal cancer prevention, J. Clin. Oncol. 2005 ;23(2): 378-391.

6. Lipska MA, Bissett IP, Parry BR, Merrie AE. Anastomotic leakage after lower gastrointestinal anastomosis: men are at a higher risk. ANZ J Surg. 2006;76:579-585

7. McArdle CS, McMillan DC, Hole DJ. Impact of anastomotic leakage on longterm survival of patients undergoing curative resection for colorectal cancer. $\mathrm{Br}$ J Surg. 2005;92:1150-1154.

8. van Westreenen HL, Visser A, Tanis PJ, Bemelman WA. Morbidity related to defunctioning ileostomy closure after ileal pouch-anal anastomosis and low colonic anastomosis. Int J Colorectal Dis. 2012; 27:49-54.

9. Chang YJ, Yan DC, Kong MS et al Nontraumatic colon perforation in children: a 10-year review. Pediatr Surg Int 2006; 22:665- 669 
10. Kenan Büyükaşık, Bünyamin Gürbulak, Emre Özoran, Yiğit Düzköylü,Esin Kabul Gürbulak, Aziz Arı, Hasan Bektaş. Indian Journal of Surgery, 2016;78(6):471-476.

11. Beirens K, Penninckx F. Procare: defunctioning stoma and anastomotic leak rate after total mesorectal excision with coloanal anastomosis in the context of Procare. Acta Chir Belg. 2012;112:10-4.

12. Tan WS, Tang CL, Shi L, Eu KW. Metaanalysis of defunctioning stomas in low anterior resection for rectal cancer. $\mathrm{Br} \mathrm{J}$ Surg. 2009;96:462-472.

13. Matthiessen P, Hallbook O, Rutegard J, Simert G, Sjodahl R. Defunctioning stoma reduces symptomatic anastomotic leakage after low anterior resection of the rectum for cancer: a randomized multicenter trial. Ann Surg. 2007;246:207-14.

14. B.R. Phillips, L.J. Harris, P.J. Maxwell, et al., Anastomotic leak rate after low anterior resection for rectal cancer after chemoradiation therapy, Am. Surg. 2010;76: 869-871.

15. S. Farth, L. Hulten, Loop ileostomy: a superior diverting stoma in colorectal surgery, World J. Surg. 1984;8: 401-407.

16. Güloğlu R, ArıcıC, Tabak $B$ et al Nontraumatik kolonperforasyonları. Kolon ve Rektum Hastalıkları Dergisi ,1995;5: 148-151.

17. Mesfin yohannes, Muluken Fanta, Tesfahun Molla, Proportion of intestinal obstruction and associated factors among patients with non traumatic acute abdomen admitted to surgical ward in Debre Birhan Referral hospital, North east Ethiopia; American Journal of Biomedical and Life Sciences, 2017;5(3):54-62.

18. Hellinger M D Steinhagen R M Colonic volvulus New York: Springer; 2009;1: 286-298.

19. Meyer F, Marusch F, Koch A, Meyer L, Führer S, Köckerling F, German Study Group "Colorectal Carcinoma (Primary
Tumor)" et al Emergency operation in carcinomas of the left colon: value of Hartmann's procedure. Tech Coloproctol ,2004;8(1):226-229.

20. Abdelrazeq AS, Scott N, Thorn C et al The impact of spontaneous tumour perforation on outcome following colon cancer surgery. Colorectal Dis,2008; 10:775-780.

21. Hartmann H. Nouveau proceed d'ablation des cancers de la partie terminale de colon pelvien. Trentieme congress de Chirurgie, Strasbourg 1921.

22. R J Whiston, N C Armitage, D Wilcox, and J D Hardcastle, Hartmann's procedure: an appraisal, Journal of the Royal society of Medicine, 1993;86(4):205-208.

23. Desai DC, Brennan EJ, Reilly JF, Smink RD The utility of the Hartmann procedure Am J Surg, 1998; 175:152-154.

24. M. Ambreen, S. Razaque, S. Gulshan, A. Qureshi, Various complications in ileostomy construction, World Appl. Sci. J. 2007;2(3): 190-193.

25. Kaidar-Person O, Person B, Wexner SD. Complications of construction and closure of temporary loop ileostomy. J Am Coll Surg. 2005;201:759-773.

26. Garcia-Botello SA, Garcia-Armengol J, Garcia-Granero E, Espi A, Juan C, LopezMozos F, et al. A prospective audit of the complications of loop ileostomy construction and takedown. Dig Surg. 2004;21:440-446.

27. Prashant Raj Pipariya, Ajay V Menon, Aclinical study of incidence of primary repair vs intestinal stomas during emergency surgeries, their complications and morbidity, Scholars Journal of applied Medical Sciences, 2016;4(12A):42084211.

28. G. Vrakas, M.G. Pramateftakis, D. Kanellos, S. Sapidis, P. Hatzigianni, T. Tsachalis, I. Kanellos, C. Lazaridis, Defunctioning ileostomy closure following 
low anterior resection by chemotherapy, Tech. Coloproctol. 2010;14(1): 77-78.

29. Coons SJ, Chongpison Y, Wendel CS, Grant M, Krouse RS. Overall quality of life and difficulty paying for ostomy supplies in the VA Ostomy Health-Related Quality of Life Study: An exploratory analysis. Med Care. 2007;45:891-895.

30. Richbourg L, Thorpe JM, Rapp CG. Difficulties experienced by the ostomate after hospital discharge. J Wound Ostomy Continence Nurs. 2007;34:70-79. 